UDC 316.346.32-053.6

LBC C550.325.1

\title{
THE WAY OF THE FUTURE IN THE VIEWS OF TODAY'S YOUTH: EXPECTATIONS AND FEARS
}

\author{
Sofya B. Abramova \\ Ural Federal University, Ekaterinburg, Russian Federation
}

\begin{abstract}
The proposed article is devoted to the analysis of one of the most topical issues of contemporary sociology of the youth - teenagers' view about themselves, their values and their future. Based on the analysis of the personal characteristics of the youngsters of 13-17 years old the processes of selfidentifying and choice of life goals by young people are considered. The article raises the problem of the vagueness of expectations and uncertainty of life plans of today's youth. The article presents the characteristic of contradictions of selection process of the youth life orientation associated as with a complicated structure of the life plans so as with absence of a clear system of indicators of efficiency of socialization in post-industrial society. The basic characteristics of the image of the future (search for subjectivity, reflexivity, emotionality, sense of purpose), key characteristics of desirable and undesirable future are demonstrated. The relationship of the ideas of success and happiness with the values of family, work, self-fulfillment, material well-being, communication is showed. The idea of a desired future often works from the opposite premise and is formulated with "I don't want to..." and based on the fears and anxieties of youngsters to become useless, lonely, poor, drinkers, like common people, etc. This article uses the materials of in-depth interviews and focus groups carried out among the young from low-income and wealthy families and children from orphanages at the age of 13-17 years in Ekaterinburg. The results of qualitative research conducted by the author are supplemented by comparative analysis with quantitative data obtained by other researchers dealing with close issues. Streotypization and personalization of the views of young people about their future especially in a long-term life plans are revealed. The article demonstrates manifestation of the phenomenon of "epistemological errors of late modernity" on the example of self-presentation of the youngsters Ekaterinburg, when absolute confidence in their ability to achieve any of their goals leads to gret responsibility for their biography, superexpectations and as a result, strong potential frustrations and inability to adapt to objective reality.
\end{abstract}

Key words: youngsters, youth, the way of the future, life plans, success, desired future.

УДК 316.346.32-053.6

ББК С 550.325 .1

\section{ОБРАЗ БУДУЩЕГО В ПРЕДСТАВЛЕНИЯХ СОВРЕМЕННЫХ ПОДРОСТКОВ: ОЖИДАНИЯ И СТРАХИ}

\author{
Софья Борисовна Абрамова \\ Уральский федеральный университет, г. Екатеринбург, Российская Федерация
}

\begin{abstract}
Аннотация. Предлагаемый к рассмотрению материал посвящен анализу одной из наиболее актуальных тем современной социологии молодежи - представлению подростков о самих себе, своих ценностях и своем будущем. На основе анализа личностных особенностей, присущих подросткам в 13-17-летнем возрасте, рассматриваются процессы самоидентификации и выбора жизненных целей молодыми людьми. В статье поднимается проблема размытости ожиданий и неопределенности жизненных планов современных подростков. Дается характеристика противоречий процесса выбора молодежью жизненных ориентиров, связанных как со сложной структурой самих жизненных планов, так и с отсутствием четкой системы показателей эффективности социализации в постиндустриальном обществе. Показаны основные характеристики, присущ. щие образу будущего (поиск субъектности, рефлексивность, эмоциональность, целеустремленность), ключевые черты желаемого и нежелаемого будущего. Показана связь представления об успехе и счастье с (?) ценностями семьи, работы, самореализации, материального благополучия, общения. Представление о же-
\end{abstract}


лаемом будущем часто идет по типу «от обратного», формулируется через «я не хочу...» и основано на страхах и опасениях подростков - стать никому не нужными, одинокими, бедными, пьющими, такими, как все и т. п. В статье использованы материалы глубинных интервью и фокус-групп, проведенных среди подростков из малообеспеченных и обеспеченных семей, а также воспитанников детских домов в возрасте 1317 лет в г. Екатеринбурге. Результаты качественного исследования, проведенного автором, дополняются сравнительным анализом с количественными данными других исследователей близкой проблематики. Раскрыта стереотипизированность и индивидуализированность представлений молодежи о своем будущем, особенно в дальних жизненных планах. Показано проявление феномена «эпистемологической ошибки поздней современности» на примере самопрезентации подростков г. Екатеринбурга, когда абсолютная уверенность в своих возможностях по достижению любых поставленных целей приводит к гиперответственности за свою биографию, сверхожиданиям и, как следствие, потенциальным сильным разочарованиям и неспособности адаптироваться к объективной реальности.

Ключевые слова: подростки, молодежь, образ будущего, жизненные планы, успех, желаемое будущее.

\section{Введение}

Современные публикации, посвященные российской молодежи, практически всегда затрагивают проблему противоречивости системы ценностей и смысложизненных позиций молодого поколения. Научные дискуссии, общественно-публицистические программы и политические программы акцентируют внимание на многомерности, неоднозначности социокультурной ситуации в современной России.

С одной стороны, это связывают с поликультурностью социального пространства, в границах которого проходит социализация современных детей, с другой - особенностями самого данного поколения. Социологи предлагают различные определения нового поколения, которые наиболее точно могли бы выразить его суть и ключевую характеристику: «generation MeMeMe - поколение ЯЯЯ», «поколение семейных карьеристов», «консервативных индивидуалистов», «поколение спокойного натиска», «амбициозных приживал», «между всем и ничем», «цифровое поколение», «поколение Z».

Социологический взгляд на развитие молодежи делает акцент на проблемах эффективности социализации и мобильности, которые должны обеспечить воспроизводство общества. На индивидуальном уровне это выражается в личностном представлении об успехе, формировании образа желаемого будущего и стремлении достигнуть референтных для личности групп. Жизненные планы могут быть представлены в виде иерархической структуры, связанной с различными уровня- ми развития личности, что определяет специфические особенности их формирования, проявления и функционирования. Так, А.В. Наприс [7] дает следующую характеристику жизненных планов:

- близкие планы - соответствуют низшему уровню направленности личности (желания, влечения); преимущественно функционально-динамические по характеру и направлены на реализацию поведения;

- средние планы - появляются при среднем уровне развития личности (интересы, стремления); направлены на развитие общения в различных сферах жизни и имеют ситуационный и событийный характер;

- дальние планы - формируются при высшем уровне развития направленности личности (идеалы, убеждения); имеют ценностносмысловой характер: жизненное самоутверждение, достижение идеала и успеха в жизни.

Цели и ценности молодых людей выступают как базовые компоненты жизненного личностного плана различного уровня. При этом характерной чертой современности становится конфликт ценностей, когда традиционные и модернистские ценности могут вступать в противоречие друг с другом как в обществе в целом, так и в ориентациях отдельной личности. Усугубляет это противоречие ситуация неопределенности - отсутствует система четких требований к нормативной личности и эффективной социализации как с точки зрения современного, так и будущего общества. В результате этого снижается результативность предсказательных возможностей социализации детей: они должны быть готовы ко всему, обладать множеством ком- 
петенций, иметь высокий адаптивный потенциал, поскольку неизвестно, что пригодится в жизни и как изменится социум. Формирование и осмысление своих жизненных планов подростком реализуется как противоречивый, неоднократно повторяемый процесс, основанный на соотнесении ценностей традиционных и новых, ориентированных на самоутверждение личности, в связи с чем возникают индивидуальные жизненные стратегии (средние планы), связанные с выделением приоритета жизненных сфер и определенных событий, снимающих это противоречие для конкретной личности.

Таким образом, в условиях многообразия норм и ценностей, которые все одновременно являются допустимыми, главной задачей (и проблемой) молодежи становится осуществление выбора. Неопределенность и наличие рисков выбора порождают страх и неуверенность, что осложняет постановку жизненной цели, формирования ценностного сознания и самоидентификации. Соответственно, вопрос о том, как осуществляется этот выбор, становится ключевым в социологическом понимании ценностей и жизненных планов молодежи.

\section{Методология и методика исследования}

Стоит обратить внимание на роль возрастных особенностей в процессе формирования жизненных планов и значение успеха в них. Современные исследования подтверждают, что юношеский возраст 13-17 лет является сензитивным для исследуемого процесса в силу сформированности необходимых личностных образований и психических способностей, и отмечают его следующие характерные особенности:

1. Происходит интенсивное развитие системы ценностных ориентаций и самосознания индивида, что становится основой его самопроектирования [1].

2. Увеличивается спектр потенциального социоролевого выбора.

3. Основной направленностью становится «устремленность в будущее»: для личности определяющее значение начинает иметь будущее, успешность деятельности и появляется необходимость в планировании.
4. Происходит окончательное формирование субъектности личности, ее активности, способности к рефлексии и т. д., что актуализирует задачу построения своего будущего и достижения поставленных целей (целеполагание). Человек становится способен корректировать собственную практическую деятельность и жизнь, критически оценивать свои действия и их результаты.

5. Способность к рефлексии дает возможность выстроить для себя перспективу «прошлое - настоящее - будущее».

6. Идет самоидентификация личности через соотнесение собственных представлений о себе с общественными, и как результат - осознанное и самостоятельное планирование перспектив собственного развития.

По мнению специалистов, именно представления о будущем выступают в качестве внугриличностного элемента, который отражает внугренние, глубинные убеждения человека, но при этом подвержен внешним воздействиям [5]. Опираясь на подходы К.А. АбульхановойСлавской, М.А. Белугиной, Е.Н. Корнеевой, Н.А. Логиновой, М.В. Осориной, Ю.М. Резника, С. Л. Рубинштейн, А.А. Тюкова и др., можно рассмотреть следующие этапы формирования жизненной стратегии личности:

1. Занятие рефлексивной позиции, принятие установки на формирование будущего своей собственной жизни. Здесь ретроспективная рефлексия имеет дело с уже свершившейся, осуществленной деятельностью, а проспективная рефлексия носит опережающий характер и направляет будущую деятельность на достижение успеха, акцентирует мышление на представлении о потенциально возможных событиях и их последствиях. Рефлексия в единстве ретроспективной и проспективной дает анализ жизненных обстоятельств с точки зрения условий формирования желаемого будущего.

2. Выбор культурных и ценностных ориентаций. Результатом этого выбора становится индивидуальная иерархия жизненных ценностей личности, а процесс выбора детерминирован общим культурным развитием человека и его способностью ориентироваться во всем многообразии норм и ценностей общественной жизни.

3. Целеопределение как процесс постановки цели. Происходит осознание желаемого бу- 
дущего, определение уровня притязаний, конструирование модели личностного успеха. Соотношение целей и ценностей личности может становиться источником внутренних противоречий и конфликтов с социальным окружением.

4. Проектирование и конструирование системы событий для достижения желаемого будущего. На основе анализа возможных путей достижения и их рисков выбирается оптимальный, определяются промежуточные этапы. Происходит выбор способа поведения и принятия решений, что определяет и степень социальной активности личности.

5. Создание структурированного плана будущего пути. Личность имеет подробный жизненный план достижения целей. В нем достижение одних целей не противоречит достижению других и работает на реализацию ключевой жизненной цели [2].

В г. Екатеринбург на основе качественной стратегии (4 фокус-группы и 10 полуформализованных интервью) было проведено исследование молодежи в возрасте 1317 лет. В проекте приняли участие подростки из малообеспеченных и обеспеченных семей, а также воспитанники детских домов. Инструментарий был адаптирован к возрасту и социально-психологическим характеристикам участников, были использованы следующие методики:

1. Обсуждение интернет-статусов (ВКонтакте). Предварительно отобранные для каждой возрастной группы интернет-статусы (высказывания) сверстников были сгруппированы в 10 категорий. На фокусгруппах эти высказывания подвергались сортингу и обсуждению.

2. Методика диагностики ценностей Ш. Шварца. Данный подход используется в Европейском социальном исследовании (European Social Survey) [12], из которого был использован элемент «Портретный опросник».

3. Метод коллизий для изучения высокосензитивных тем. Участникам предъявлялись истории с описанием реалистичной острой ситуации; им предлагалось оценить поведение героев, предложить свою позицию.

4. Рисуночные методики. Участникам предлагалось нарисовать свое желаемое и нежелаемое будущее, затем рисунки комментировались и обсуждались.

\section{Результаты исследования}

Кризис 13 лет - это кризис социальноличностного развития, похожий на кризис 3 лет («Я сам»), однако теперь акцент переносится на «Я сам» в социальном смысле. Часто этот кризис сопровождается снижением работоспособности, падением успеваемости, дисгармоничностью, негативизмом и критичностью. Базальная потребность возраста - понимание. Как отмечает И.С. Кон, психологически возраст 14-17 лет «крайне противоречив. Юношеское чувство - чувство взрослости - главным образом новый уровень притязаний, предвосхищающий положение, которого молодой человек фактически еще не достиг» [6, с. 66]. Ранний юношеский возраст специалист характеризуют как сложный, переходный, критический и имеющий определяющее значение в процессе становления личности человека: в этот период качественно изменяется характер, формируются нравственные представления, увеличивается число сфер жизнедеятельности и самовыражения [13, с. 38].

Следовательно, можно предположить, что доминирующее описание будущего сквозь призму эмоций - это не попытка поставить моральные качества и душевное состояние превыше материальных благ или формальных признаков успеха, а стремление считать, что эмоции могут быть отражением этих достижений: «Если идеальный образ в будущем, то у меня это личная семья, то есть своя женщина, жена, дети... суметь обеспечить свою семью, прокормить, все одеть, обутыл и счастливы.»

Эмоциональность, радость, легкость присутствуют в устремлениях информантов и «сами по себе», и в качестве определяющей характеристики других целевых ориентиров - отношений, учебы, работы: «обычно стремятся к какой-то радости там, веселью, чему-то такому... И вообще, как бы это сказать, к свободе, независимости от родителей, от обстоятельств каких-то». Отсюда самое главное выражение желаемого будущего у подростков - позитивное эмоциональное состояние. Поэтому надо постараться «объединить картинку в сердие, потому что все должно делаться с любовью... а также позитив должен 
быть». Эти данные согласуются с выводами исследования, проведенного социологами УрГПУ среди школьников Свердловской области: в интерпретации успеха школьниками среди наиболее часто встречающихся ассоциаций отмечены счастье, бурные положительные эмоции ( $36 \%$ ) и «достижение цели» (34\%) $[8$, c. $74-75]$.

Практически у всех участников образ будущего сильно стереотипизирован, мало кто представляет картину какого-то особенного, сверхоригинального будущего. Составляющие желаемого будущего - это семья, работа, а также символы достатка, материального благополучия - дом и машина. Эти элементы встречаются либо все вместе, либо в разных сочетаниях: «Желаемое будущее - это дом, я, семья моя. То есть ребенок, муж, солнышко светит, все ярко, все красочно, машина».

Представления о будущем у подростков из детского дома отличаются сильным акцентом на счастливую семью, где люди заботятся друг о друге: «...чтоб у меня была счастливая семья, не такая, как у меня была в детстве». Счастливая семья - это «хорошая мать и хороший отеи, чтоб работали, заботились, чтоб дом был. Счастливая семья - у которой все есть, которые любят друг друга, заботятся друг о друге, волнуются».

Приоритетная ценность семьи в целом не означает, однако, что молодые люди стремятся первым делом образовать собственную семью. Напротив, чаще всего семья отодвигается в отдаленную перспективу, после получения образования, работы, достижения определенного материального достатка: «Я нарисовал себя с любимым человеком... Высшее образование получить, на работу, хорошую зарплату получать, семью образовать».

Планы на получение образования сегодня очень связаны с социально-экономическими возможностями семьи. Например, по данным исследования «Старшеклассник-2009: портрет на фоне кризиса» Фонда Общественного Мнения, 22 \% старшеклассников считают, что текущий экономический кризис повлиял или изменил их планы продолжить образование, при этом среди жителей села и среди девушек это мнение встречается чаще. Наи- более распространенная причина корректировки планов - возникшие сложности с оплатой образования [14].

Отодвигая семью в неопределенное будущее, в ряде случаев подростки воспринимают будущее исключительно через самореализацию в работе: «Работать, как все нормальные люди». Но и здесь эмоциональный компонент превалирует над материальным (принципиально важным, но тем не менее вторичным). Работа должна нравиться - такое убеждение высказывается информантами независимо от возраста и достатка. Так, «обеспеченные» ребята 13-14 лет желаемое и нежелаемое будущее противопоставляют именно по критерию любимой и нелюбимой работы: «Я бы не хотела работать с бумагами в орисах, что-то считать, в какихто стопках бумаг - для меня это просто ужасно». Эта мысль усиливается у другого участника: «Ну конечно, в наше время трудно выбирать себе профессию по призванию... Но я считаю, что главное все равно, чтобы человеку нравилось то, что он хочет делать».

Сравнивая результаты проведенного исследования с результатами исследования А.Д. Галюк, можно увидеть некоторые различия. Например, в исследовании данного автора школьники связывают успех прежде всего со счастливой семьей, возможностью иметь детей, также они считают успехом наличие друзей. Только на третьем месте стоит высокий заработок, который не связан с любимой работой $[4$, с. 89$]$.

Однако гораздо более важным для подростков 13-17 лет оказывается личностное саморазвитие. Эта идея постоянно вклинивается в их рассуждения, накладывая на стереотипизированные представления отпечаток поколенческого выбора. Целеустремленность как проявление субъектности становится доминирующей чертой их видения своего будущего.

Прежде всего отметим целеустремленность как общую позицию информантов относительно их жизненных целей. Целеустремленность выступает как готовность ставить цели и вера в их достижимость. 14-летний воспитанник детского дома считает, что для того, чтобы стать поваром, как он хочет, нуж- 
но «поставить перед собой иель, помочь должно желание». Целеустремленность выступает своеобразным залогом и гарантом желаемого будущего: главное - иметь желания, ставить цели, и все получится. 17-летний студент колледжа не хотел бы стать нецелеустремленным, поскольку «если иель будет, то сможешь, наверное, все».

Современное общество культивирует целеустремленность, это важный элемент достижительской культуры и проявление субъектности. Убежденность молодого человека в том, что перед ним открыты все дороги и его судьба в его руках, придает ему уверенность в своих силах, энтузиазм и действительно работает на реальные достижения. Примером реализации субъектной позиции может послужить случай Нади. Ей не понравилось в Березовском детском доме: «...omношения у меня там были плохие... сама написала письмо в министерство, чтобы меня перевели, и меня перевели сюда». Сориентироваться и переломить ситуацию в свою пользу ей помогла не только специфическая социальная компетентность, общение с друзьями своего круга, но и отсутствие страха, что «не получится».

В то же время оборотной стороной культа целеустремленности является феномен, названный западными социологами «эпистемологической ошибкой поздней современности». Будучи всецело уверенными в своих возможностях, молодые люди не видят базовых ограничений, проистекающих из социального неравенства, которое приобретает новые формы в современном обществе, но отнюдь не исчезает. Катастрофическим следствием эпистемологической ошибки является гиперответственность за собственную биографию, которая непомерным грузом ложится на плечи молодых. В приведенных мнениях наблю- даются явные признаки эпистемологической ошибки: «Я понимаю, что в намем возрасте все в наших руках... В первую очередь нужна вера в себя, ты все можешь. Если есть иель, значит есть пути к ней, поставил цель - иди».

Как показывают результаты опроса россиян (см. таблицу), эта тенденция возлагать ответственность за свои успехи (а тем более неудачи) на себя будет неуклонно снижаться с возрастом [10].

Целеустремленность активизируется в поворотных точках жизненного пути, для изучаемых молодых людей это - окончание учебного заведения. Информанты видят «большие перемены», произошедшие за последние полгода в поведении друзей, в сети «ВКонтакте»: «Если раньше были затасканные статусы про любовь, то сейчас появились статусы иели, поставь себе ичель».

Этот поиск субъектности связан с особым вниманием, которое подростки начинают уделять сравнению себя с другими людьми, литературными героями, даже родителями и другими референтными группами. Безусловно, с одной стороны, они ищут подтверждения правильности своих представлений, своей особости и возможности именно ему отказаться от «стандартного пути»: «Мне очень понравилось, недавно мысль нашла из Ницше про то, что жизнь стоит прожить так, чтобы ты не боялся вечного ее повторения. И я подумала, что мне очень не хочется тратить ее на достижение вот этих каких-то формальных иелей, я лучше буду тратить ее на какое-то саморазвитие». Но с другой стороны, если говорить о нормативной системе, для современных молодых людей очень важна субъектная позиция, когда они сами «изобретают» свои правила и нормы. Это не означает отказа от вечных или

Ответственность за успехи и неудачи в жизни в оценках разных возрастных групп (\% от числа опрошенных)

\begin{tabular}{|l|c|c|c|c|}
\hline & \multirow{2}{*}{ Все } & \multicolumn{4}{|c|}{ Возраст } \\
\cline { 3 - 5 } & & $18-35$ лет & $36-50$ лет & старше 50 лет \\
\hline Успехи в жизни - это... & 71 & 78 & 70 & 66 \\
\hline результат собственных усилий & 21 & 19 & 24 & 21 \\
\hline удачное стечение обстоятельств & \multicolumn{5}{|l|}{} \\
\hline Неудачи в жсизни - это... & 55 & 64 & 57 & 46 \\
\hline результат собственных ошибок & 33 & 27 & 36 & 35 \\
\hline неудачное стечение обстоятельств &
\end{tabular}


родительских ценностей в целом, они просто не хотят их принимать на веру, а стремятся к осмысленному созиданию своей системы жизненных координат [3, с. 68].

Поэтому рефлексивность становится основой их рассуждений о будущем. По наблюдениям социологов рефлексивность является отличительной чертой современного человека, в особенности молодого, что обнаруживается в размышлениях юных екатеринбуржцев: "Так четко сформировалась картина моего мира, наверно, года два назад, так вот четко, что я смогла сформулировать и аргументировать. До этого не задумывалась: я есть и есть, зачем копаться в себе, выстраивать, словами объяснять». Отсюда формируется представление, что жизненные планы должны быть реалистичны и отличаться от пустых мечтаний: «Желать, что бессмысленно, это глупо, а желать чего-то, что реально, не просто желать $и$ мечтать, а ставить цеели».

В разговоре 15-17-летних (малообеспеченных) подростков возникла характерная для современных молодых людей тема неопределенности будущего, которая проявляется в отказе от долговременного планирования. В результате такие «реалисты» сознательно ограничивают себя «ближайшими целями». Желаемое будущее обозначается очень условными чертами и не имеет пространственного и временного контекста: «У меня нет сейчас никаких иелей, я не могу пока их себе поставить: если я буду двигаться к иели, а потом что-то пойдет не так, и все сломается».

Видимо, поэтому многим подросткам проще начать с описания того, какими они не хотели бы стать в будущем, - атрибуты социально неодобряемого образа более конкретны и их проще обрисовать. Можно выделить несколько базовых концептов, определяющих образ нежелаемого будущего у подростков:

А. Вредные привычки - бутылка, сигарета, шприц, пистолет, нож. Символам вредных привычек сопутствует атрибутика нищеты, социальной исключенности, заброшенности: «порванные итань»», «на бомжей похожи». Особо отметим, что зачастую представления о будущей жизни у детей из детских домов противоречивы, обладают крайними позициями (сверх пессимистичны или оптимистичны), нечетко сформулированы и ограничены близкими жизненными планами. Так, 26 \% выпускников этих заведений опасаются «спиться, скатиться, попасть в тюрьму»; $13 \%$ страшатся какого-либо насилия («убьют, ограбят, изобьют»); неудач в личной жизни ожидают $17 \%$. Напротив, 40 \% выпускников детских домов сверх оптимистичны в своих ожиданиях, а их мечты неоправданно «радужные»: «Будущее шоколад. Я директор, на меня все работают» $[11$, с. 62].

Б. Мусор (мусорный бак, дворник, помойка). Это важный и неоднозначный символ. В восприятии ребят помойка ассоциируется с недозволенным, точно так же, как и выпивка, курение, употребление наркотиков. Вместе с тем помойки и свалки обладают определенной привлекательностью для детей. Известный детский психолог М.В. Осорина отмечает, что подобные места ощущаются не только как грязные, но и манят большим количеством степеней свободы, «обилием возможностей и сюрпризов» [9, с. 124]. Двойственность помойки в «мире детей» предполагает, что не одобряемые взрослым обществом занятия могут быть притягательны. Информанты не лукавят, они по-взрослому играют во взрослые игры: помойка, как и курение, насыщена значениями творческих возможностей, волшебных переходов. Велик, однако, и потенциал (само)разрушительного действия, к которому подталкивает, по М. Осориной, тема перехода из одного состояния в другое (из жизни - в смерть, из формы - в бесформенную кучу, из целого - в элементы), заключенная в семантике свалки.

Другой вариант нежелаемого будущего, также связанный с мусором, - это стать уборщицей, дворником: «Я конечно не хочу работать дворником или уборщицеей, но жизнь показывает, что ими могут работать люди с высшим образованием».

Еще ниже по социальной лестнице располагаются нищие, и их образ пугает и вызывает жалость: «Одинокой и как-то, не знаю, унижать себя, что я могу копаться в мусорке... Просто грусть вот». В ходе исследования возникла категория «нечеловек». Это бомж - «получеловек, полуживотное». Важно, что в восприятии подростков бомж символизирует не только социальное дно, но и 
одиночество. Бомж - это тот, от кого все отвернулись, возможно, он стал таким потому, что у него не было поддержки. И в этом возрасте уже присутствует осознание диалектического перехода: иногда люди меняются в бомжей, и наоборот, из бомжа можно превратиться «в человека», «их тоже считают за людей, с ними некоторые дружат».

В. Отсутствие символов обеспеченной жизни - дома, автомобиля. Отличие «обеспеченных» 13-14-летних - они развили тему о том, что не хотели бы быть очень богатыми. «Я не хочу быть сильно богатым человеком, потому что у них меняется характер, они чувствуют власть, поэтому они становятся жадными, все очень плохо делают. Они думают только о себе и деньгах».

Г. Одиночество. Ослабленность социальных связей, отдаление от социально одобряемых ценностей дают неприкаянность, неукорененность в ячейках общества, которые придавали бы определенность и защищенность. Человек оказывается ни к чему и ни к кому не привязан, находится непонятно где это значит «где-нибудь ходить-бродить без дома, без крыши над головой, без семьи». Одиночество концентрирует в себе целый ряд смыслов, которые противостоят в представлениях молодых людей желаемому будущему:

1) одиночество как отсутствие социальных связей, поддержки друзей и знакомых - не с кем справить день рождения;

2) отсутствие желаний, целей - ослабление или полное растворение социальных связей с их ориентирами, когда человеку становится безразлично все, что ценится другими и заставляет их действовать;

3) одиночество как разрушение норм бытового обихода, когда человек становится неухоженным, неопрятно при этом выглядит;

4) как чувствуют себя при этом (грустно, печально, плачут);

5) одиночество как отсутствие материальных составляющих благополучия, прежде всего дома. Человек оказывается без крыши над головой, на лавочке или у мусорки.

Таким образом, у подростков планирование жизненной перспективы характеризуется низкой субъективной вероятностью ее реализации. Это можно объяснить тем, что вместо постановки жизненных целей принимается не- кий образ себя в будущем, опирающийся, с одной стороны, на какой-либо стереотип построения жизненного пути, а с другой - реализацию индивидуальных способностей и интересов. Неопределенность будущего как характерная черта постиндустриального общества определяет отсутствие долговременного планирования: «просматриваемое будущее» у исследуемой возрастной группы - примерно до 25 лет; можно предположить, что к 30 годам подростки рассчитывают максимально достичь всех желаемых благ. Подростки в целом оптимистично смотрят в свое будущее; опасения связаны с внешними обстоятельствами, которые могут затруднить достижение целей, но не помешать успешному продвижению как таковому, поскольку даже объективные обстоятельства не могут быть оправданием недостижения поставленной цели.

В заключение отметим, что образ желаемого будущего связан в первую очередь с восприятием подростком себя как счастливого человека, что обусловлено характерными особенностями данного возрастного этапа. Поэтому понимание представлений подростка невозможно без учета как социальных, так и внутриличностных факторов, определяющих процесс его социализации.

\section{СПИСОК ЛИТЕРАТУРЫ}

1. Белинская, Е. П. Представления подростков о своем социальном будущем / Е. П. Белинская, И. В. Куликова // Мир психологии. - 2000. - № 4. С. $135-147$.

2. Белугина, М. А. Структура и динамика формирования жизненной стратегии в юношеском возрасте / М. А. Белугина // Ярославский педагогический вестник. - 2008. - № 4 (57). - С. 109-111. - Электрон. текстовые дан. - Режим доступа: http://vestnik. yspu.org/releases/psihologiya/41_2/ (дата обращения: 30.03.2017). - Загл. с экрана.

3. Веселкова, Н. В. Социальная компетентность взросления / Н. В. Веселкова, Е. Прямикова. Екатеринбург : Изд-во Урал. ун-та, 2005. - 290 с.

4. Галюк, А. Д. Особенности представлений молодежи о жизненном успехе в современной России : дис. ... канд. социол. наук ; Урал. гос. ун-т им. А. М. Горького / Галюк Алена Дмитриевна. Екатеринбург, 2004. - 153 с.

5. Гобова, Е. С. Психологический портрет поколения. Типология представлений о себе / Е. С. Гобова, О. Н. Игнатова. - Электрон. текстовые дан. - 
Режим доступа: http://psy.1 september.ru/article.php? $\mathrm{ID}=200700612$ (дата обращения: 15.04.2017). - Загл. с экрана.

6. Кон, И. С. Психология ранней юности : Кн. для учителя / И. С. Кон. - М. : Просвещение, 1989. - 255 с.

7. Наприс, А. В. Теоретические и методические вопросы исследования личностных жизненных планов и их влияния на поведение осужденных молодежного возраста / А. В. Наприс. - Рязань : Узорочье, $2003 .-258 \mathrm{c}$.

8. Образовательное пространство школы: опыт социологических исследований : [коллектив. моногр.] / Урал. гос. пед. ун-т ; [отв. ред. Е. В. Прямикова, С. В. Франщ].-Екатеринбург : [б. и.], 2014. -244 с.

9. Осорина, М.В.Секретный мир детей в пространстве мира взрослых / М. В. Осорина. - СанктПетербург [и др.] : Питер, 2011. - 359 с.

10. Петрова, А. С. За успехи и неудачи молодежь берет ответственность на себя (опрос населения, ФОМ) / А. С. Петрова. - Электрон. текстовые дан. - Режим доступа: http://bd.fom.ru/report/cat/ home_fam/teen_cheeld/of033003 (дата обращения: 21.04.2017). - Загл. с экрана.

11. Присяжная, Н. В. Дети-сироты: постинтернатное жизнеустройство / Н. В. Присяжная // Социологические исследования. - 2007. - № 11. - С. 54-63.

12. Россия в Европе: по материалам международного проекта «Европейское социальное исследование» : [монография] / под общ. ред. А. В. Андреенковой, Л. А. Беляевой. - М. : Academia, 2009. - 383 с.

13. Семенова, Е. Г. Особенности развития активной личности подростка / Е. Семенова // Среднее профессиональное образование. - 2010. - № 8. - С. 37-39.

14. Старшеклассник-2009: портрет на фоне кризиса (опрос населения, ФОМ). - Электрон. текстовые дан. - Режим доступа: http://bd.fom.ru/report/ map/st210509 (дата обращения: 17.04.2017). - Загл. с экрана.

\section{REFERENCES}

1. Belinskaya E.P., Kulikova I.V. Predstavleniya podrostkov o svoem sotsialnom budushchem [Representations of Adolescents about Their Social Future]. Mir psikhologii, 2000, no. 4, pp. 135-147.

2. Belugina M.A. Struktura i dinamika formirovaniya zhiznennoy strategii v yunosheskom vozraste [Structure and Dynamics of Life Strategy Formation in Adolescence]. Yaroslavskiy pedagogicheskiy vestnik, 2008, no. 4 (57). URL: http://vestnik.yspu.org/releases/psihologiya/ 41_2/(accessed March 30, 2017).

3. Veselkova N.V., Pryamikova E.V. Sotsialnaya kompetentnost vzrosleniya [Social Competence of Growing Up]. Ekaterinburg, Izd-vo Uralskogo un-ta, 2005.290 p.
4. Galyuk A.D. Osobennosti predstavleniy molodezhi o zhiznennom uspekhe $v$ sovremennoy Rossii: dis. ... kand. sotsiol. nauk [Youth's Ideas about Life Success in Modern Russia. Cand. sociol. sci. diss.]. Ekaterinburg, 2004. 153 p.

5. Gobova E.S., Ignatova O.N. Psikhologicheskiy portret pokoleniya. Tipologiya predstavleniy o sebe [Psychological Portrait of Generation. Typology of SelfRepresentations]. URL: http://psy.1 september.ru/ article.php?ID=200700612 (accessed April 15, 2017).

6. Kon I.S. Psikhologiya ranney yunosti [Psychology of Early Adolescence]. Moscow, Prosveshchenie Publ., 1989. 255 p.

7. Napris A.V. Teoreticheskie i metodicheskie voprosy issledovaniya lichnostnykh zhiznennykh planov $i$ ikh vliyaniya na povedenie osuzhdennykh molodezhnogo vozrasta [Theoretical and Methodological Issues of Research on Personal Life Plans and Their Impact on Behavior of Convicted Young People]. Ryazan, Uzorochye Publ., 2003. 258 p.

8. Pryamikova E.V., Frants S.V., eds. Obrazovatelnoe prostranstvo shkoly: opyt sotsiologicheskikh issledovaniy: kollektivnaya monografiya [The Educational Space of the School: Experience of Sociological Research]. Ekaterinburg, 2014. 244 p.

9. Osorina M.V. Sekretnyy mir detey $v$ prostranstve mira vzroslykh [The Secret World of Children in the World of Adults]. Saint Petersburg, Piter Publ., 2011. 359 p.

10. Petrova A.S. Za uspekhi i neudachi molodezh beret otvetstvennost na sebya (opros naseleniya, FOM) [Young People Take Responsibility for Success and Failure (People's Poll, FOM)]. URL: http://bd. fom.ru/report/cat/home_fam/teen_cheeld/of033003 (accessed April 21, 2017).

11. Prisyazhnaya N.V. Deti-siroty: postinternatnoe zhizneustroystvo [Orphans: Post-Orphanage Life Support]. Sotsiologicheskie issledovaniya, 2007, no. 11, pp. 54-63.

12. Andreenkova A.V., Belyaeva L.A. Rossiya v Evrope: po materialam mezhdunarodnogo proekta «Evropeyskoe sotsialnoe issledovanie»: monografiya [Russia in Europe: Based on the Materials of International Project "European Social Research"]. Moscow, Academia Publ., 2009. 383 p.

13. Semenova E.G. Osobennosti razvitiya aktivnoy lichnosti podrostka [Features of Development of a Teenager's Active Personality]. Srednee professionalnoe obrazovanie, 2010, no. 8, pp. 37-39.

14. Starsheklassnik 2009: portret na fone krizisa (opros naseleniya, FOM) [Senior Student 2009: Portrait on a Background of Crisis (Poll of Population, FOM)]. URL: http://bd.fom.ru/report/map/st210509 (accessed April 17, 2017). 


\section{СОЦИОЛОГИЯ И СОЦИАЛЬНЫЕ ТЕХНОЛОГИИ}

\section{Information about the Author}

Sofya B. Abramova, Candidate of Sociological Sciences, Associate Professor, Department of Applied Sociology, Institute of Social and Political Sciences, Ural Federal University, Prosp. Lenina, 51, 620075 Ekaterinburg, Russian Federation, sofia_abramova@mail.ru.

\section{Информация об авторе}

Софья Борисовна Абрамова, кандидат социологических наук, доцент кафедры прикладной социологии Института социальных и политических наук, Уральский федеральный университет, просп. Ленина, 51, 620075 г. Екатеринбург, Российская Федерация, sofia_abramova@mail.ru. 